\title{
Influence of Abrasive Waterjet Machining Parameters on the Surface Texture Quality of Carrara Marble
}

\author{
Mohammad S. Alsoufi*, Dhia K. Suker, Mohammed W. Alhazmi, Sufyan Azam \\ Department of Mechanical Engineering, College of Engineering and Islamic Architecture, \\ Umm Al-Qura University, Makkah, KSA \\ Email: ^mssoufi@uqu.edu.sa
}

How to cite this paper: Alsoufi, M.S., Suker, D.K., Alhazmi, M.W. and Azam, S. (2017) Influence of Abrasive Waterjet Machining Parameters on the Surface Texture Quality of Carrara Marble. Journal of Surface Engineered Materials and Advanced Technology, 7, 25-37.

https://doi.org/10.4236/jsemat.2017.72003

Received: February 6, 2017

Accepted: April 17, 2017

Published: April 20, 2017

Copyright (c) 2017 by authors and Scientific Research Publishing Inc. This work is licensed under the Creative Commons Attribution International License (CC BY 4.0).

http://creativecommons.org/licenses/by/4.0/

\begin{abstract}
Abrasive waterjet (AWJ) cutting technology has been used extensively for the cutting and processing of almost all engineering materials because of its precise cutting technique and the lack of damage caused. Currently, the use of abrasive waterjet cutting in the natural stone industry is increasing. However, the effectiveness of abrasive waterjet cutting of natural stones is dependent on the rock properties and machine operating parameters. Consequently, this paper presents the influence of abrasive waterjet machining parameters on the surface texture quality of Carrara marble. The results have shown that the abrasive waterjet cutting process offers better cut surface texture quality of Carrara marble under certain parameter conditions as well as being more environmentally-friendly. The stand-off distance shows the opposite effect on both surface roughness and waviness. With a view to reducing the machining costs, every user tries to select the traverse rate of the cutting head to be as high as possible, but results show that increasing the traverse rate always causes a corresponding increase in terms of inaccuracy, surface roughness, $R_{\mathrm{a}}$ $\approx 93.7 \mu \mathrm{m}$, and waviness, $W_{\mathrm{a}} \approx 92.6 \mu \mathrm{m}$. The abrasive mass flow rate is not a significant parameter during the cutting process. In all investigations, it was found that the machined surface of the marble is smoother near the jet entrance, $R_{\mathrm{a}} \approx 4 \mu \mathrm{m}$, and waviness, $W_{\mathrm{a}} \approx 5 \mu \mathrm{m}$, and increasingly becomes rougher towards the jet exit. The result also shows that the micro-hardness value of the Carrara marble was in the range of $122 \mathrm{HV}$ to $124 \mathrm{HV}$.
\end{abstract}

\section{Keywords}

Abrasive Waterjet, Carrara Marble, Micro-Hardness, Surface Roughness, Waviness 


\section{Introduction}

With the increasing requirement for a high-quality surface texture in micrometer and nano-meter surface roughness and waviness, abrasive waterjet (AWJ) cutting technology in the sole efficient and cost-effective means [1]. The AWJ cutting technology method is one of the non-traditional machining (NTM) methods that have been used widely in a fairly considerable number of modern industry related applications. Recently, the fundamental principles of AWJ cutting technology and its promise for micro- and nano-machining was reviewed in detail by Alsoufi, M. S. [2]. This advanced technology is less sensitive to engineering material properties as it has no thermal distortion effects in the cutting zones, does not cause chatter, imposes minimal stresses on the workpiece to be cut, and has high machining versatility to cut any engineering materials and high flexibility to cut in any direction and so on. It is flexible due to close interaction with the CAD/CAM programming system [3]. Nevertheless, it has some drawbacks; especially inasmuch as it may generate considerable noise and a messy working environment around the target material. Surface texture quality is considered as one of the most vital parameters in AWJ cutting technology and in all other machining processes [4]. Figure 1 shows the geometric components of a surface profile, including the surface roughness, $R_{\mathrm{a}}$, waviness, $W_{\mathrm{a}}$, and form, $P_{\mathrm{a}}$. The key indication of the degree of quality of the surface on the machined parts is the surface roughness, $R_{\mathrm{a}}$, along with the waviness, $W_{\mathrm{a}}$, and the mean value of the surface roughness is defined as stated in Equation (1) as [2]:

$$
R_{a}=\frac{1}{L} \int_{0}^{L}|y| d x
$$

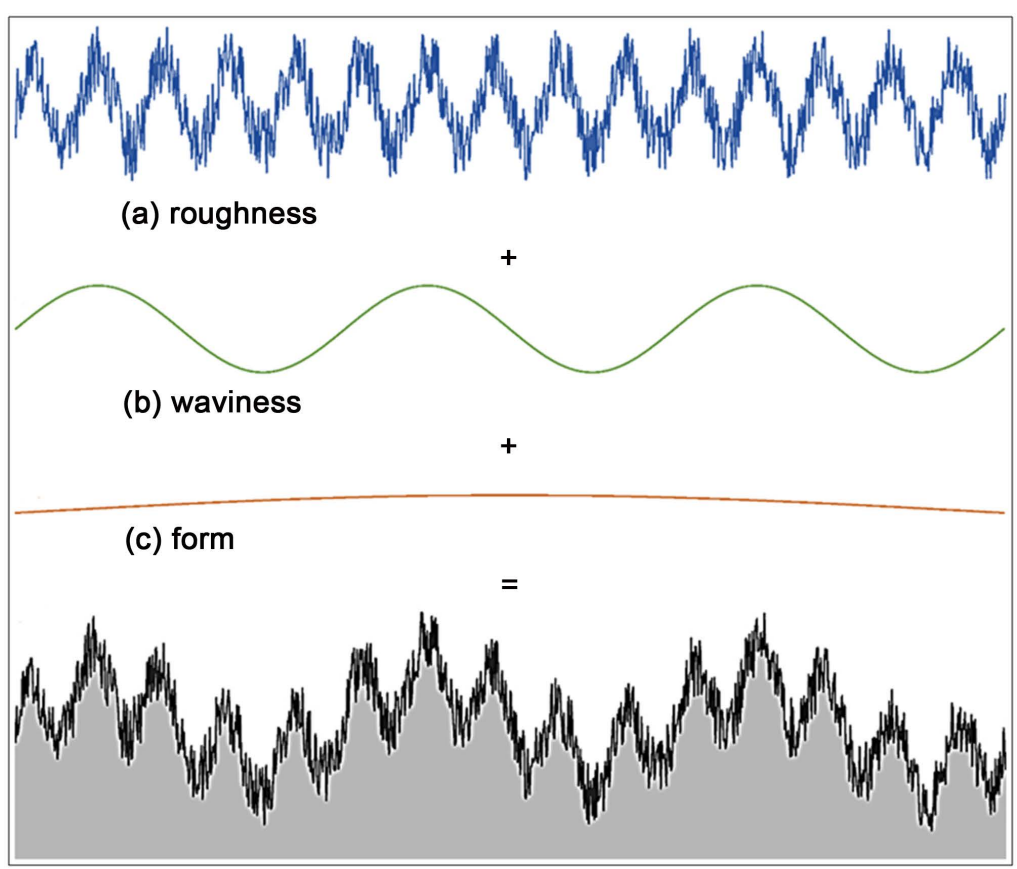

Figure 1. Geometric components of a surface profile: (a) roughness; (b) waviness and (c) form. 
where $L$ is the profile length being evaluated and $y=f(x)$ is the profile measured from the mean reference line. Based on the surface quality level and applications, cost will play the major part in fulfilling the customer's requirements. The surface texture quality, also known as surface finish or surface topography, is one of the most specific client requirements, and the primary indicator of the quality of the surface finish on machined parts is, $R_{\mathrm{a}}$, along with the waviness, $W_{\mathrm{a}}$. The surface roughness, $R_{\mathrm{a}}$, is primarily a result of many controllable or uncontrollable machining process parameters, and it is harder to attain and track than physical dimensions are. A significant number of investigations have researched the effects of the water pressure, traverse rate, abrasive grain size, stand-off distance, and other machining process factors on the $R_{\mathrm{a}}$ and $W_{\mathrm{a}}$ [5] [6] [7]. Hence, it is essential to acquire a deeper knowledge and understanding of the optimum working conditions, which will permit the investigators to ensure an excellent surface roughness, $R_{\mathrm{a}}$, and waviness, $W_{\mathrm{a}}$. The purpose of this study is therefore to examine the effects of AWJ variables such as traverse rate, stand-off distance and abrasive mass flow rate on surface roughness, $R_{\mathrm{a}}$, and waviness, $W_{\mathrm{a}}$, in AWJ cutting of Carrara marble. Variation in surface roughness across the depth of cut is also examined along with the surface micro-hardness.

\section{Experimental Materials and Methods}

In the present study, an experimental investigation has been carried out to find the effect of process parameters such as stand-off distance, traverse rate and abrasive mass flow rate on the surface texture generated by AWJ. Carrara marble (as used in Al-Masjid Al-Haram, The Holy Mosque, in Makkah, KSA, for internal flooring and internal/external cladding application) with an identical size of $100 \mathrm{~mm} \times 10 \mathrm{~mm} \times 40 \mathrm{~mm}$ cut out of the boards of greater dimensions in a longitudinal direction by an AWJ machine and with different process parameters. The basic mechanical and physical properties of the target material are listed in Table 1. The surface irregularity distribution and the micro-hardness were measured using the conventional contact-type Taly-Surf profilometer (Taylor Hobson Precision, Inc.) and Vickers indentation micro-hardness (Microhardness, Zwick Roell Indentec ZHV1-AFC, Germany), respectively. Details of the surface roughness measurements procedure have been reported elsewhere [8] [9] [10] [11] [12] and the micro-hardness measurements procedure has also been reported elsewhere [9] [10] [11] [12] [13]. Measuring was conducted in six zone levels per each sample.

In AWJ cutting technology, a narrow and focused pure water jet is mixed with garnet abrasive particles (water with stone). This narrow jet of AWJ is sprayed in the zones with an ultra-high pressure system (UHPS), capable of providing maxi-

Table 1. Mechanical and physical properties of Carrara marble.

\begin{tabular}{cccccccc}
\hline Property & Hardness & Density & $\begin{array}{c}\text { Compressive strength } \\
\text { (dried test condition) }\end{array}$ & $\begin{array}{c}\text { Compressive strength } \\
\text { (wet test condition) }\end{array}$ & $\begin{array}{c}\text { Water } \\
\text { absorption }\end{array}$ & $\begin{array}{c}\text { Porosity } \\
\text { impact }\end{array}$ \\
\hline Value & $122-124 \mathrm{HV}$ & $3.755 \mathrm{~kg} / \mathrm{m}^{3}$ & $16.5 \mathrm{MPa}$ & $18.9 \mathrm{MPa}$ & Less than $1 \%$ & Quite Low & Resistant \\
\hline
\end{tabular}


mum water pressure around $400 \mathrm{MPa}$, resulting in high velocity that cut through Carrara marble quickly. The velocity of the stream is approximately $90 \mathrm{~m} / \mathrm{s}$, which is around 3.0 times the speed of sound. The presence of garnet abrasive particles in the waterjet (mixing chamber) reduces cutting forces and permits the cutting without difficulty of thick and/or very hard materials, such as diamond. During the experiments, a $0.3 \mathrm{~mm}$ of high wear resistance nozzle was regularly checked and replaced with a new one whenever the sapphire nozzle was worn-out or damaged significantly. With high-pressure AWJ cutting technology, the cutting process is achieved. The constant and variable process parameters of the AWJ cutting technology are shown in Table 2 and Table 3, respectively. The sapphire nozzle was fixed at a supporting frame, whose traverse across and vertical movement were accurately operated through a precision control panel system. All tests were conducted using garnet abrasive particles (a mesh size of approximately $180 \mu \mathrm{m}(80 \#)$ ) with an impingement angle of $90^{\circ}$ and density of $4100 \mathrm{~kg} / \mathrm{m}^{3}$. In the literature review [14], it was noted that 80 mesh garnet is the optimum type and accurate size in most applications in industrial operations of AWJ. Garnet abrasive particles (GMA Garnet ${ }^{\mathrm{TM}}$ ) are composed of natural Almandite rock garnet grains that are known for their natural hardness, sharp edges, durability, increased angularity and abrasive characteristics. Figure 2 shows the image of the Carrara marble and the layout of AWJ cutting directions.

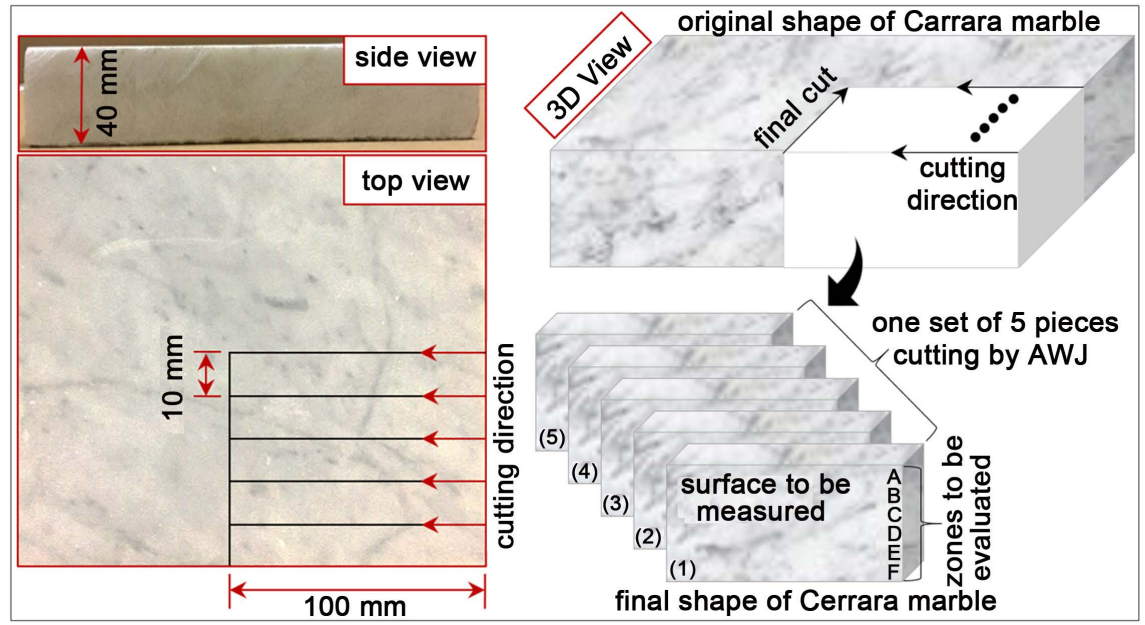

Figure 2. Illustration of AWJ cutting on Carrara marble.

Table 2. Constant parameters and their operating values.

\begin{tabular}{cc}
\hline Parameters & Operating value \\
\hline Water pressure, $\mathrm{MPa}$ & 400 \\
Water orifice diameter, $\mathrm{mm}$ & 0.3 \\
Focusing tube diameter, $\mathrm{mm}$ & 0.8 \\
Focusing tube length, $\mathrm{mm}$ & 76 \\
Abrasive particle & 80 \\
Abrasive material & Australian garnet GMA \\
\hline
\end{tabular}


Table 3. Variable parameters and their operating values.

\begin{tabular}{cc}
\hline Parameters & Operating value \\
\hline Stand-off distance, $\mathrm{mm}$ & $4,8,12,16,20$ \\
Traverse rate, $\mathrm{mm} / \mathrm{min}$ & $2,4,6,8,10$ \\
Abrasive mass flow rate, $\mathrm{g} / \mathrm{min}$ & low, medium, high \\
\hline
\end{tabular}

Each set of AWJ cutting contains five pieces of Carrara marble with an identical size of $100 \mathrm{~mm} \times 10 \mathrm{~mm} \times 40 \mathrm{~mm}$, including constant and variable cutting process parameters.

\section{Experimental Results and Analysis}

Surface roughness, $R_{\mathrm{a}}$, and waviness, $W_{\mathrm{a}}$, measurements are made at different zone levels of the Carrara marble surface. Figure 3 shows the surface behaviour of Carrara marble created by the AWJ machine. In this work, the effect of the process parameters such as stand-off distance, traverse rate and abrasive mass flow rate on the $R_{\mathrm{a}}$ and $W_{\mathrm{a}}$ during AWJ cutting of a $100 \mathrm{~mm}$ thick Carrara marble plate were analyzed. From analysing the experimental data outcomes, it has been found that the influence of the process parameters on the $R_{\mathrm{a}}$ and $W_{\mathrm{a}}$ are in the same fashion as reported in previous studies for other materials [15]-[20]. The effects each of these process parameters is investigated while keeping the other process parameters fixed. These extracted data results provide vital metallurgical information.

\subsection{Performance Parameters on $R_{\mathrm{a}}$ and $W_{\mathrm{a}}$}

Surface roughness, $R_{\mathrm{a}}$, and waviness, $W_{\mathrm{a}}$, are the most important criteria, which helps the researchers to determine how rough/smooth a workpiece material is machined. The general behavior of the Carrara marble cut surface produced by AWJ can be seen in Figures 4-6 for both surface roughness and waviness. In this study, fluctuations of stand-off distance, traverse rate, and abrasive mass flow rate play a significant role in striation pattern and result in striation irregularities. The surface roughness and waviness were measured in 6 different lines starting at a distance of $0.5 \mathrm{~mm}$ from the top edge of the sample zone (A) and ending at a distance of $0.5 \mathrm{~mm}$ from the bottom edge of the material zone (F). Each measurement of $R_{\mathrm{a}}$ and $W_{\mathrm{a}}$ was taken three times, and their arithmetic mean was calculated so as to minimize error. In all the investigations, it was found that the quality of the machined surface finish for the Carrara marble is smoother near the jet entrance (top surface) and increasingly becomes rougher towards the jet exit (bottom surface). This is since, as the particles move down, they lose their kinetic energy (KE) and their cutting ability deteriorates. Besides this, it is also caused by many machining parameters.

Clearly, the surface texture of the sample after cutting by AWJ divided into two different zones namely a "smooth zone" which is free-face surface of any striations and a "striation zone" where the striations (wavy structures) are domi- 


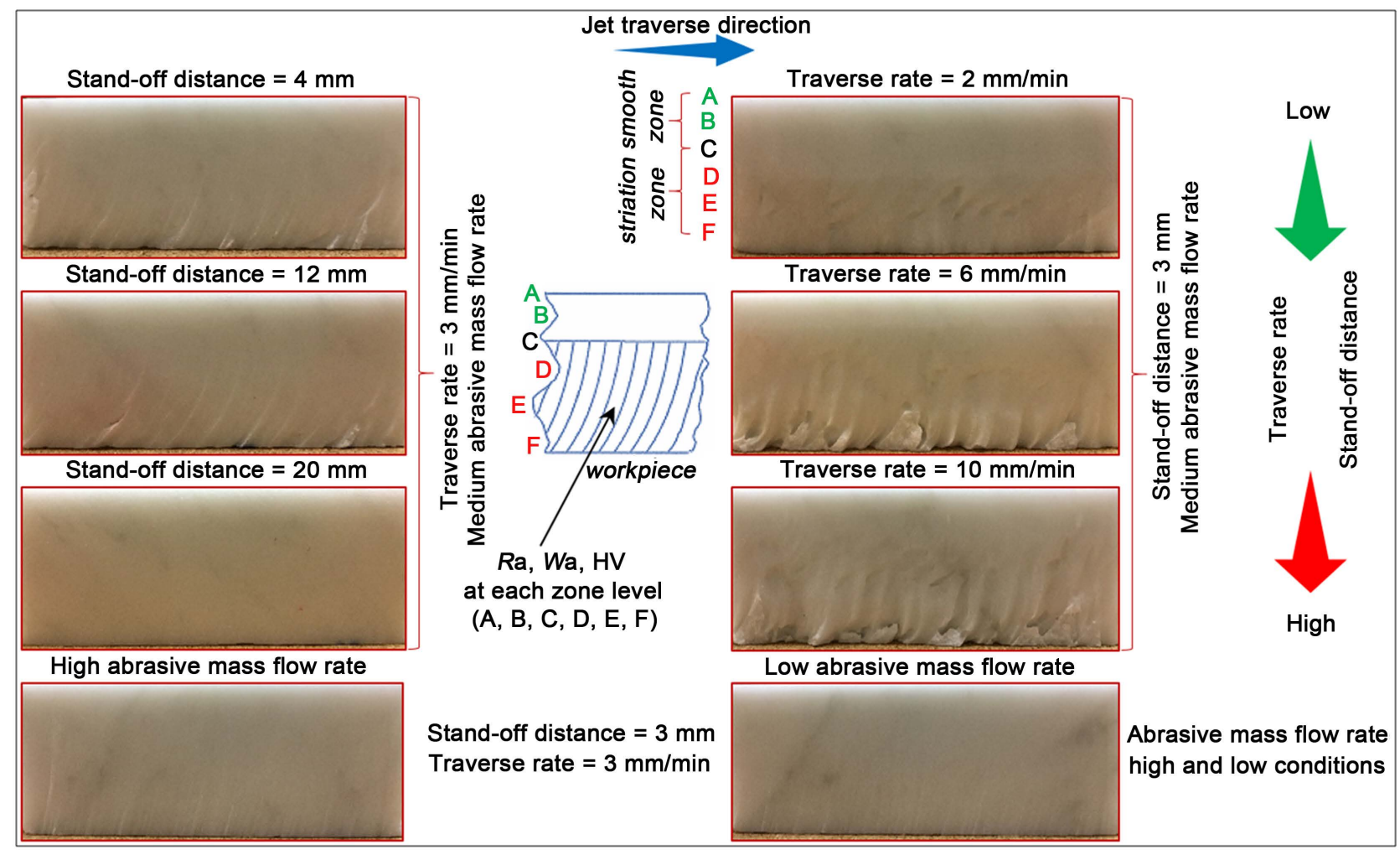

Figure 3. Illustration of AWJ cutting on Carrara marble.
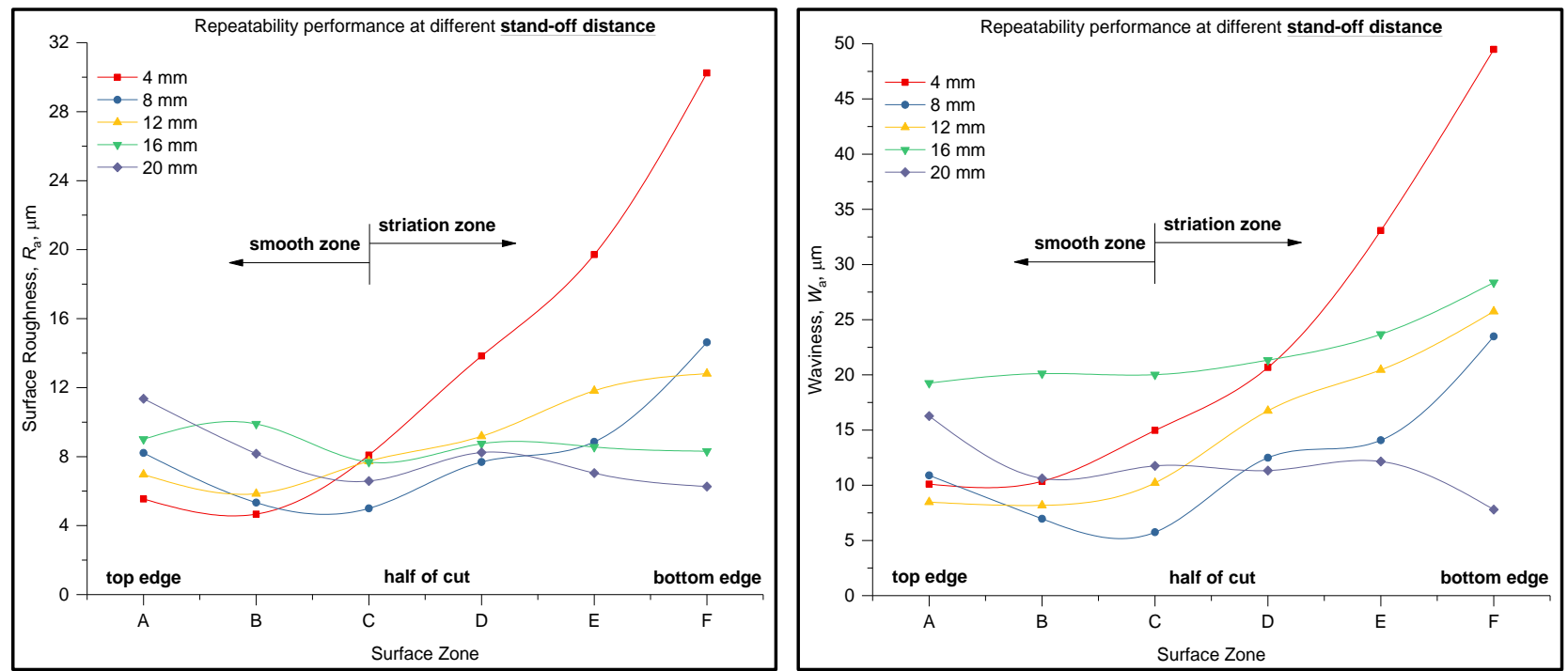

Figure 4. Effect of different stand-off distance on the surface roughness and waviness of Carrara marble.

nant characteristic features of the deformation wear zone. The striation formation mechanism is still not very well understood. Possible causes of formation striations found in the literature [6] [16] [21] [22] are (a) vibration during the cutting process, (b) the undulatory distribution of the KE of the abrasive particles inside the jet and (c) decrease of KE of the jet with the depth of cut (DoC). The striation formation irregularities are thought to be caused by the wavy abrasive particles' KE magnitude distribution related to the cut surface. Also, the 

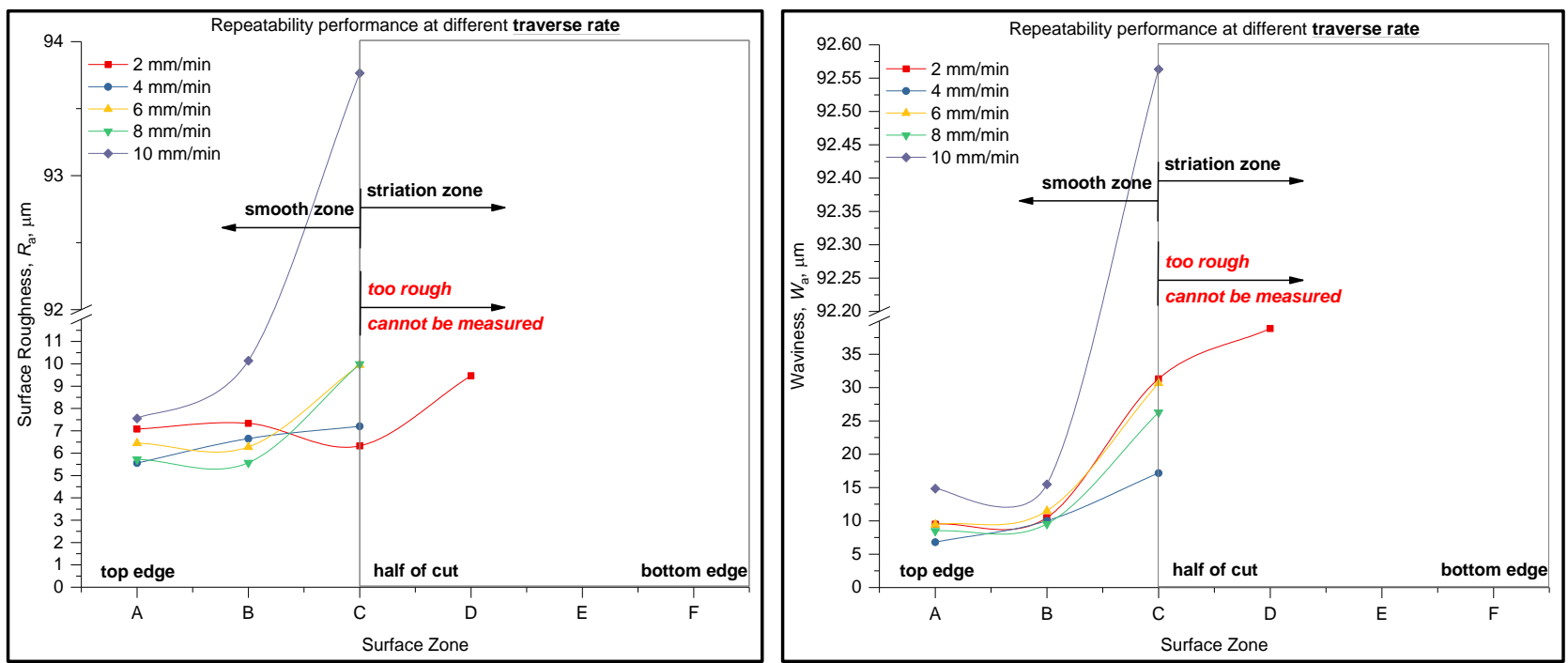

Figure 5. Effect of different traverse rate on the surface roughness and waviness of Carrara marble.

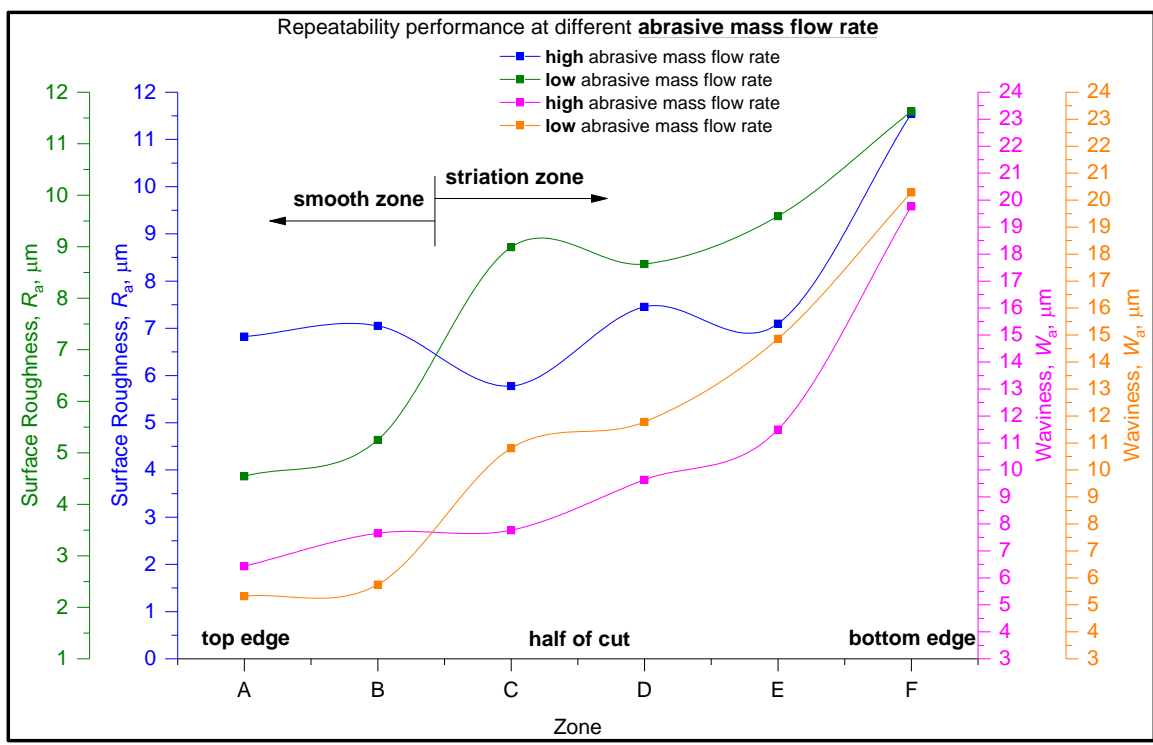

Figure 6. Effect of different abrasive mass flow rate on the surface roughness and waviness of Carrara marble.

striation drag angle (trail back) depends on the ratio between the jet vertical penetration rate and traverse rate. As the cutting depth increases, the jet cutting power becomes fairly small, and so the jet vertical penetration rate decreases and the traverse rate remains constant. Thus, the ratio between the jet vertical penetration rate and traverse rate increases and so the striation drag angle (trail back) becomes larger at the bottom edge of the sample as the cutting depth increases. Hypothetically, it is almost impossible to eliminate the striation behaviour marks on the cutting surface by AWJ cutting technology or any other non-traditional cutting methods. However, by selecting proper process parameters, it becomes possible to control the surface quality adequately.

During cutting processes in the upper zone $(\mathrm{A}, \mathrm{B}, \mathrm{C})$ of the sample, the abrasive particles have higher $\mathrm{KE}$ than the required destruction energy of the Carrara 
marble so that the whole cut surface can be cut through without difficulty, and a smooth surface $R_{\mathrm{a}}$ and $W_{\mathrm{a}}$ can be achieved. In the "smooth zone", the surface roughness and waviness values of Carrara marble are relatively stable, and that is why the lowest $R_{\mathrm{a}}$ and $W_{\mathrm{a}}$ values were found in that zone $\left(R_{\mathrm{a}} \approx 4 \mu \mathrm{m}, W_{\mathrm{a}} \approx 5\right.$ $\mu \mathrm{m})$. As the cutting depth increases, the number of the garnet abrasive particles decreases, that is the effective jet vertical diameter decreases and the KE distribution profile of the wave-particle turns out to be very sharp. The strong garnet abrasive particles cluster at the forefront continues to cut through the marble surface while the weak trailing cluster of particles is unable to do so on account of its degree of energy and is therefore unable to follow the stronger particle traces. This leaves crest-to-trough wave trace marks on the target material. In the "striation zone", the surface roughness and waviness values of Carrara marble are relatively unstable, and that is why the highest $R_{\mathrm{a}}$ and $W_{\mathrm{a}}$ values were found in that zone $\left(R_{\mathrm{a}} \approx 94 \mu \mathrm{m}, W_{\mathrm{a}} \approx 92 \mu \mathrm{m}\right)$ and significant deterioration of the surface quality is observed. The surface shows a corrugated and grooved structure. The grooves are slightly rounded and oriented opposite to the cutting direction.

In the case of stand-off distance, as shown in Figure 4, the surface roughness and waviness of the Carrara marble represent the smoothest surface pattern $\left(R_{\mathrm{a}}\right.$ $\approx 11.3 \mu \mathrm{m}$ and $\left.W_{\mathrm{a}} \approx 16.3 \mu \mathrm{m}\right)$ in the top edge and show fewer striation irregularities $\left(R_{\mathrm{a}} \approx 6.3 \mu \mathrm{m}\right.$ and $\left.W_{\mathrm{a}} \approx 7.8 \mu \mathrm{m}\right)$ in the bottom edge of the sample at 20 $\mathrm{mm}$ stand-off distance. Whereas, at $4 \mathrm{~mm}$ stand-off distance, the surface roughness, $R_{\mathrm{a}}$, and waviness, $W_{\mathrm{a}}$, reached the maximum value of $R_{\mathrm{a}} \approx 30.2 \mu \mathrm{m}$ and $W_{\mathrm{a}}$ $\approx 49.5 \mu \mathrm{m}$ at the bottom edge of the sample. Indeed, it is necessary to have a low value of stand-off distance which might generate a smooth machined surface as a result of increased the KE at the upper zone. The machined surface area of Carrara marble is smoother nearer the top edge of the surface and it turns out to be rougher at greater depths from the top edge of the surface. In this trend, decreasing the stand-off distance reduces the surface roughness slightly in the zone (A, B). Nevertheless, it is believed that the machined laminate surface might not be optimized for minimum stand-off distance. Higher stand-off distance allows the jet vertical to expand just before impingement which might increase vulnerability to external drag from the adjacent environment. Also, if the stand-off distance is relatively small, the abrasive mass flow rate is decelerated or damped by the target machined surface that generates a depth of cut which is very shallow. After that, the surface roughness, $R_{\mathrm{a}}$, increased dramatically in the zone (C, $\mathrm{D}, \mathrm{E}, \mathrm{F})$.

In the case of traverse rate, as shown in Figure 5, it can be predicted that as increasing the traverse rate allows significantly less overlap machining process action and fewer garnet abrasive particles to impinge on the machined surface, there will be an increase in the surface roughness by $R_{\mathrm{a}} \approx 93.7 \mu \mathrm{m}$, and an increase in the waviness by $W_{\mathrm{a}} \approx 92.6 \mu \mathrm{m}$. The overall trend of the data outcomes shows that increase in traverse rate from $2 \mathrm{~mm} / \mathrm{min}$ to $10 \mathrm{~mm} / \mathrm{min}$ results in an increase in $R_{\mathrm{a}}$ and $W_{\mathrm{a}}$. The data was only obtained in the zone (A, B) as the other zone area of the Carrara marble surface becomes too rough and difficult to measure. This is due to the fact that a faster traverse rate increases the jet deflec- 
tion which results in a higher magnitude of surface roughness and waviness. So, the cut sample was considered unacceptable at a speed rate of $10 \mathrm{~mm} / \mathrm{min}$, as the $R_{\mathrm{a}}$ and $W_{\mathrm{a}}$ have been unable to be measured in the zone (D, E, F). The cut has a $\mathrm{V}$-shaped profile and at the bottom striations (roughness) are formed. In this rate, a low value of traverse rate is required to generate a better machined surface quality.

In the case of abrasive mass flow rate, as shown in Figure 6, the higher the abrasive mass flow rate, the higher the number of garnet abrasive particles involved in the mixing chamber, as well as total $\mathrm{KE}$ available and cutting processes. An increase in abrasive mass flow rate leads to a direct proportional increase in the depth of cut (DoC) of the marble. When the abrasive mass flow rate is increased, the jet vertical can cut through the machined laminate surface without difficulty and thus, the cut machined surface roughness and waviness becomes smoother $R_{\mathrm{a}} \approx 4.5 \mu \mathrm{m}$ and $W_{\mathrm{a}} \approx 5.3 \mu \mathrm{m}$. However, the surface roughness and waviness increases, $R_{\mathrm{a}} \approx 11.6 \mu \mathrm{m}$ and $W_{\mathrm{a}} \approx 20.2 \mu \mathrm{m}$, with a rise in abrasive mass flow rate up to a certain limit as illustrated in Figure 6 . This is since an increase in the mass of garnet abrasive particles results in inter-collision of the natural Almandite rock garnet grains between themselves and hence causes a loss of KE during the cutting process. It is evident that the machined surface is smoother nearby the jet vertical entrance and the $R_{\mathrm{a}}$ and $W_{\mathrm{a}}$ value increases steadily towards the jet exit.

The traverse rate is the advance rate of the nozzle on a horizontal plane per unit time during the AWJ cutting procedure. Figure 7 shows the influence of traverse rate on the depth of cut $(\mathrm{DoC})$ at a stand-off between the orifice and the Carrara marble of $3 \mathrm{~mm}$ and $0.3 \mathrm{~mm}$ water orifice diameter. Apparently, results

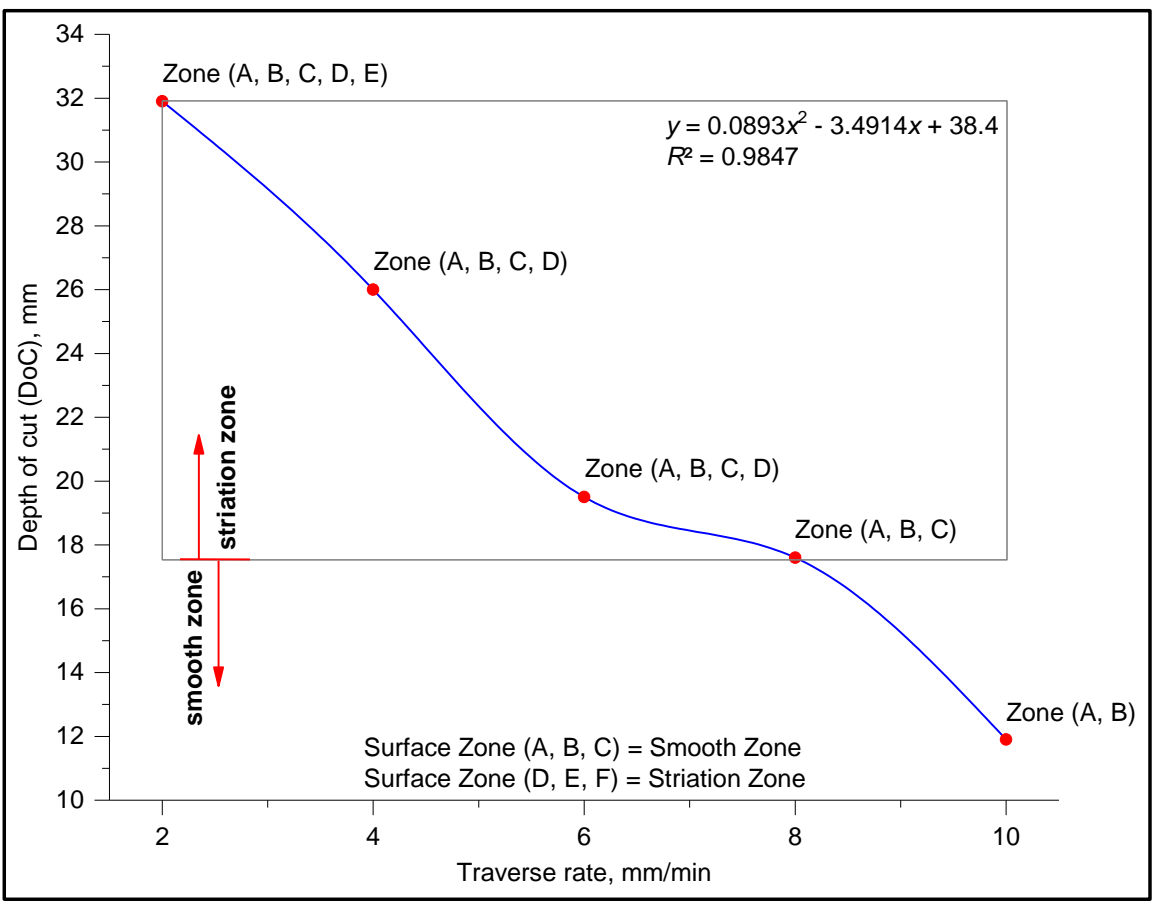

Figure 7. Depth of cut vs. traverse rate. 
indicate that the DoC decreased with an increase in the traverse rate from 2 $\mathrm{mm} / \mathrm{min}$ to $10 \mathrm{~mm} / \mathrm{min}$, within the operating range selected. The decline in $\mathrm{DoC}$ is a direct result of the exposure time, as at a higher traverse rate less time is available for cutting the target, leading to not as much overlapping of the jet vertical on the Carrara marble. Besides, the water with abrasive particles from the narrow jet does tend to get into the micro cracks in the Carrara marble and because of the resulting hydro-dynamic pressure, micro-crack growth occurs. When the micro-cracks connect and grow, the included material will break loose from the parent material and the DoC increases. Therefore, it appears sensible to assume that an inverse relationship exists between the DoC and traverse rate. On the other hand, stand-off distance is the distance between the nozzle and the workpiece during the cutting operation. The increase in nozzle stand-off distance decreased the DoC when the other parameters considered in this study remained constant. Also, cutting depth is a good measure of the natural stone resistance to AWJ cutting process, although it is not the same as the precise cutting process energy linked to the removed debris during AWJ cutting. However, stand-off distance on DoC is not particularly influential when compared to the traverse rate.

\subsection{Performance Parameter on Micro-HV}

The surface hardness of the Carrara marble is determined using the Vickers micro-hardness indentation test as per the standard loading procedure. A series of a load of $10,25,50,100,200,300,500$ and $1000 \mathrm{~g}$ is applied to the test specimen using a $136^{\circ}$ diamond indenter for a duration of 15 seconds. The micro-HV measurements were taken at ten points being randomly selected on the surface of samples as a function of depth from the treated surface, and the mean value of the surface micro-hardness was determined by calculating the arithmetic mean of these values. Figure 8 shows the normal Q-Q plot for micro-hardness values of Carrara marble. The output range value of the micro-hardness was between $122 \mathrm{HV}$ to $124 \mathrm{HV}$.

In AWJ cutting technology applications, abrasion resistance, hardness and density together form the strength of the target material because this cutting technique is a micro-machining process and any other process whose material removal mechanism is an erosion-based process. For example, when a natural stone (such as Carrara marble) tile is intended to be used on the floor of a crowded place as used in Al-Masjid Al-Haram, The Holy Mosque, in Makkah, KSA, it has to show high values of hardness.

\section{Conclusions and Remarks}

Experimental investigations have been carried for the surface roughness, $R_{\mathrm{a}}$, and waviness, $W_{\mathrm{a}}$, during AWJ cutting of Carrara marble along with the surface micro-hardness. The influence of different operational parameters such as standoff distance, traverse rate and abrasive mass flow rate on $R_{\mathrm{a}}$ and $W_{\mathrm{a}}$ have been investigated. Through this study, it is observed that these operational parameters 


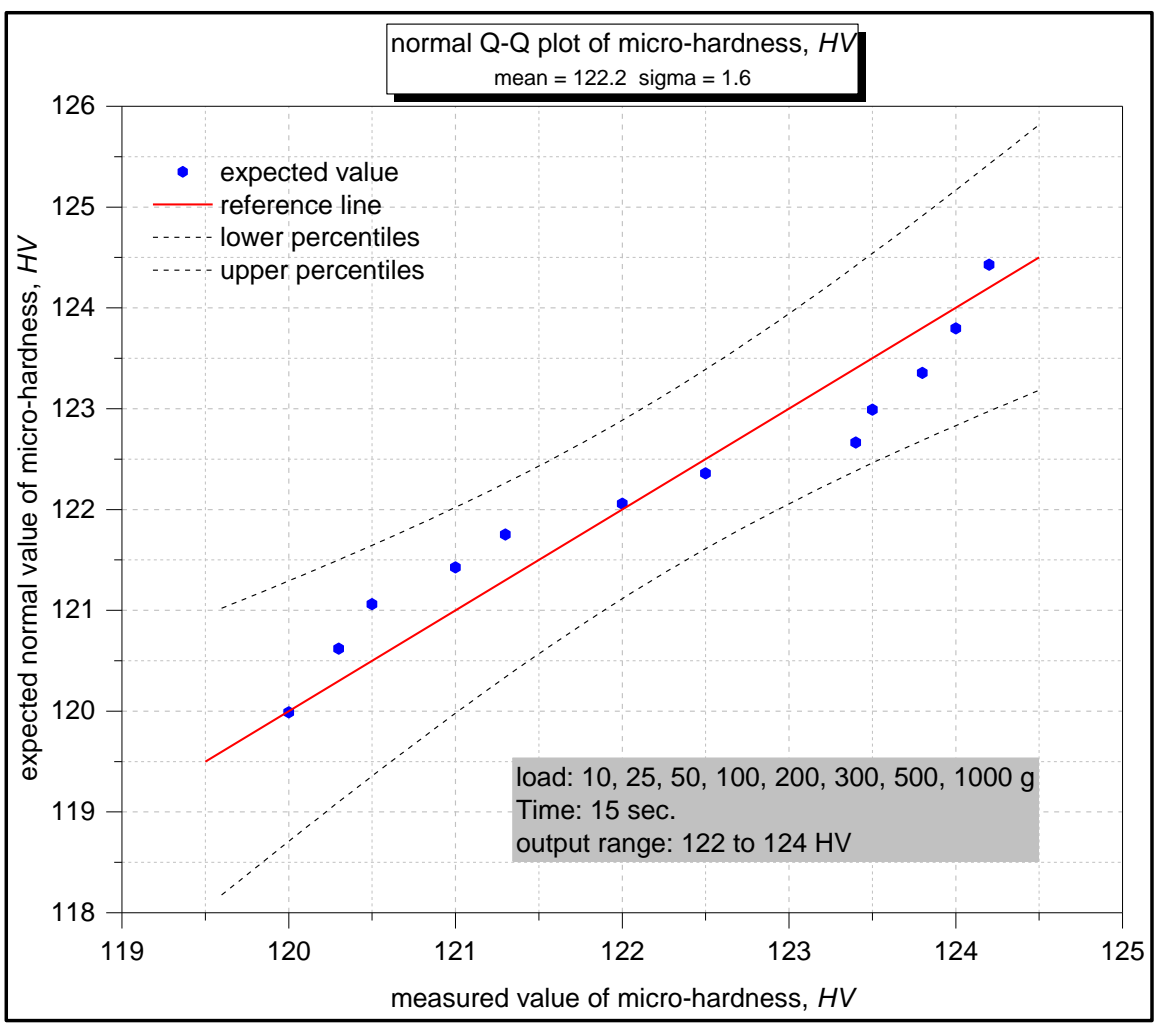

Figure 8. Normal Q-Q plot for micro-hardness values of Carrara marble.

have both a direct and indirect effect on $R_{\mathrm{a}}$ and $W_{\mathrm{a}}$. The accurate and efficient use of the AWJ machine for cutting the Carrara marble, to a large degree, depends on the right choice of process parameters. The surface being cut by AWJ was characterized at a different zone level (A, B, C, D, E, F). Zone (A) was located at the beginning of the cut and was considered a smooth machined surface. Zone (F) was, in contrast, located at the ending of the cut and was considered a rough machined surface and the machined surface quality deterioration is observed. The conclusions were as follows:

- The stand-off distance and traverse rate show an opposite effect on both $R_{\mathrm{a}}$ and $W_{\mathrm{a}}$ during the AWJ cutting method.

- The traverse rate over the workpiece is the most significant machining parameter on both $R_{\mathrm{a}}$ and $W_{\mathrm{a}}$ during the AWJ cutting method. Low values of $R_{\mathrm{a}}$ and $W_{\mathrm{a}}$ values required a high number of abrasive particles per unit area; such conditions result from a lower traverse rate. The feasible solution is the selection of medium value of the traverse rate through which can be achieved greater efficiency with tolerable machined surface texture quality.

- The abrasive mass flow rate is considered not a significant machining parameter on both $R_{\mathrm{a}}$ and $W_{\mathrm{a}}$ during the AWJ cutting method. Also, to reduce processing phase costs, the abrasive mass flow rate might be reduced to the manufacturer's suggested value, as the $R_{\mathrm{a}}$ and $W_{\mathrm{a}}$ to some degree change by increasing the abrasive mass flow rate. This means that a low value of the traverse rate should be used to obtain more machined surface smoothness but then again this is at the cost of sacrificing productivity. 
- It is confirmed that increasing the $\mathrm{KE}$ of an abrasive waterjet might generate a better quality of cuts for the final product of the Carrara marble.

Finally, searching for new possibilities regarding how to increase the efficiency of the cutting of difficult-to-cut materials is an essential task of future research.

\section{Acknowledgements}

The authors would like to express their sincere thanks and appreciation for the project of the Custodian of the Two Holy Mosques King Abdullah Bin Abd Al-Aziz for Mataf Extension providing Carrara marble as workpiece materials for this investigation.

\section{Conflicts of Interest}

The authors have no conflicts of interest.

\section{References}

[1] Zhang, S.J., To, S., Wang, S.J. and Zhu, Z.W. (2015) A Review of Surface Roughness Generation in Ultra-Precision Machining. International Journal of Machine Tools and Manufacture, 91, 76-95.

[2] Alsoufi, M.S. (2017) State-of-the-Art in Abrasive Water Jet Cutting Technology and the Promise for Micro- and Nano-Machining. International Journal of Mechanical Engineering and Applications, 5, 1-14.

[3] Mostafa, M.A.G., Alsoufi, M.S. and Tayeb, B.A. (2015) CAD/CAM Integration Based on Machining Features for Prismatic Parts. International Journal of Emerging Trends \& Technology in Computer Science, 4, 106-110.

[4] Abdullah, R., Mahrous, A. and Barakat, A. (2016) Surface Quality of Marble Machined by Abrasive Water Jet. Cogent Engineering, 3, Article ID: 1178626. https://doi.org/10.1080/23311916.2016.1178626

[5] Kovacevic, R. (1991) Surface Texture in Abrasive Waterjet Cutting. Journal of Manufacturing Systems, 10, 32-40.

[6] Akkurt, A., Kulekci, M.K., Seker, U. and Ercan, F. (2004) Effect of Feed Rate on Surface Roughness in Abrasive Waterjet Cutting Applications. Journal of Materials Processing Technology, 147, 389-396.

[7] Axinte, D.A., Srinivasu, D.S., Kong, M.C. and Butler-Smith, P.W. (2009) Abrasive Waterjet Cutting of Polycrystalline Diamond: A Preliminary Investigation. International Journal of Machine Tools and Manufacture, 49, 797-803.

[8] Alsoufi, M.S. and Bawazeer, T.M. (2015) The Effect of Aggressive Biological Materials on a Painted Automotive Body Surface Roughness. American Journal of Nano Research and Applications, 3, 17-26.

[9] Alsoufi, M.S., Suker, D.K., Alsabban, A.S. and Azam, S. (2016) Experimental Study of Surface Roughness and Micro-Hardness Obtained by Cutting Carbon Steel with Abrasive Waterjet and Laser Beam Technologies. American Journal of Mechanical Engineering, 4, 173-181.

[10] Bawazeer, T.M., Alsoufi, M.S., Katowah, D. and Alharbi, W.S. (2016) Effect of Aqueous Extracts of Salvadora Persica "Miswak" on the Acid Eroded Enamel Surface at Nano-Mechanical Scale. Materials Sciences and Applications, 7, 754-771. https://doi.org/10.4236/msa.2016.711059

[11] Alsoufi, M.S. and Bawazeer, T.M. (2015) Quantifying Assessment of Touch-Feel 
Perception: An Investigation Using Stylus Base Equipment and Self-Touch (Human Fingertip). Umm Al-Qura University Journal of Engineering and Architecture, 1, 116.

[12] Suker, D.K., Alsoufi, M.S., Alhusaini, M.M. and Azam, S.A. (2016) Studying the Effect of Cutting Conditions in Turning Process on Surface Roughness for Different Materials. World Journal of Research and Review (WJRR), 2, 16-21.

[13] Alsoufi, M.S., Alhazmi, M.W., Ghulman, H.A., Munshi, S.M. and Azam, S. (2016) Surface Roughness and Knoop Indentation Micro-Hardness Behavior of Aluminium Oxide $\left(\mathrm{Al}_{2} \mathrm{O}_{3}\right)$ and Polystyrene $\left(\mathrm{C}_{8} \mathrm{H}_{8}\right)_{\mathrm{n}}$ Materials. International Journal of Mechanical \& Mechatronics Engineering, 16, 43-49.

[14] Holmqvist, G. and Honsberg, U. (2008) Sensitivity Analysis of Abrasive Waterjet Cutting Economy. Proceeding of 19th International Conference on Water Jetting, University of Nottingham, Nottingham, 273-287.

[15] Selvan, M.C.P., Raju, N.M.S. and Rajavel, R. (2011) Effects of Process Parameters on Depth of Cut in Abrasive Waterjet Cutting of Cast Iron. International Journal of Scientific \& Engineering Research, 2, 1-5.

[16] Chen, F.L. and Siores, E. (2001) The Effect of Cutting Jet Variation on Striation Formation in Abrasive Water Jet Cutting. International Journal of Machine Tools and Manufacture, 41, 1479-1486.

[17] Hascalik, A., Caydas, U. and Gurun, H. (2007) Effect of Traverse Speed on Abrasive Waterjet Machining of Ti-6Al-4V Alloy. Materials and Design, 28, 1953-1957.

[18] Kartal, F., Yerlikaya, Z. and Gökkaya, H. (2017) Effects of Machining Parameters on Surface Roughness and Macro Surface Characteristics When the Machining of Al-6082 T6 Alloy Using AWJT. Measurement, 95, 216-222.

[19] Mutavgjic, V., et al. (2011) Experimental Investigation of Surface Roughness Obtained by Abrasive Water Jet Machining. 15th International Research/Expert Conference "Trends in the Development of Machinery and Associated Technology" TMT201, Prague, Czech Republic.

[20] Duspara, M., Palatinuš, T., Samardžić, I., Marić, D., Starčević, V. and Stoić, A. (2016) Influence of Abrasive Feeding and Cutting Direction on the Surface Roughness. Procedia Engineering, 149, 48-55.

[21] Wang, J. (1999) Abrasive Waterjet Machining of Polymer Matrix CompositesCutting Performance, Erosive Process and Predictive Models. The International Journal of Advanced Manufacturing Technology, 15, 757-768. https://doi.org/10.1007/s001700050129

[22] Aydin, G., Karakurt, I. and Aydiner, K. (2011) An Investigation on Surface Roughness of Granite Machined by Abrasive Waterjet. Bulletin of Materials Science, 34, 985-992. https://doi.org/10.1007/s12034-011-0226-x 
Submit or recommend next manuscript to SCIRP and we will provide best service for you:

Accepting pre-submission inquiries through Email, Facebook, LinkedIn, Twitter, etc. A wide selection of journals (inclusive of 9 subjects, more than 200 journals)

Providing 24-hour high-quality service

User-friendly online submission system

Fair and swift peer-review system

Efficient typesetting and proofreading procedure

Display of the result of downloads and visits, as well as the number of cited articles Maximum dissemination of your research work

Submit your manuscript at: http://papersubmission.scirp.org/

Or contact jsemat@scirp.org 